\title{
The Significance of Colour Design in Creating Comfort at Sports Facilities
}

\author{
Mariia A. Sennikova, Aleksandr I. Chikurov \\ and Aleksandr L. Voinich* \\ Siberian Federal University \\ Krasnoyarsk, Russian Federation
}

Received 31.10.2020, received in revised form 24.12.2020, accepted 27.01.2021

\begin{abstract}
The paper discusses the significance of colour design of sports facilities in the aspect of creating psychophysiological comfort for their visitors. The study was conducted in two stages. The first one consisted of a survey in the form of a questionnaire: two groups of 289 respondents expressed their view on the importance of comfort as well as of basic indicators of comfort that sports facilities provide. The results of the study showed that comfort, interior styling and colour design of a sports facility are vital and not of least importance for different categories of visitors to sports facilities. The second stage was carried out by an expert assessment method (the Delphi method), during which the colour design of the sports training block (STB) "Snezhnyi" (Sopka Cluster, Krasnoyarsk) was evaluated regarding the level of psychophysiological comfort it creates for its customers. The result of the conducted expert assessment has showed that the level of psychophysiological comfort created by the colour decoration of STB "Snezhnyi" is evaluated as "close to high" and "high". The research has revealed that colour solutions used in the design of sports facilities can be important in creating psychophysiological comfort for visitors and, therefore, can be used as one of the success factors in developing a marketing strategy for sports facilities.
\end{abstract}

Keywords: sports facility, psychophysiological comfort, significance of comfort, colour design.

Research area: physical education.

Citation: Sennikova, M.A., Chikurov, A.I., Voinich, A.L. (2021). The significance of colour design in creating comfort at sports facilities. J. Sib. Fed. Univ. Humanit. Soc. Sci., 14(2), 206-213. DOI: $10.17516 / 1997-1370-0712$.

\footnotetext{
(C) Siberian Federal University. All rights reserved

* Corresponding author E-mail address: Aleksandr.Voynich@mail.ru, Kikoro@mail.ru, Chikurov71@mail.ru ORCID: 0000-0002-5915-2629 (Sennikova); 0000-0003-0172-4898 (Voinich)
} 


\title{
Значение цветового оформления в создании комфорта на спортивных объектах
}

\author{
М.А. Сенникова, А.И. Чикуров, А.Л. Войнич \\ Сибирский федеральный университет \\ Российская Федераиия, Красноярск
}

\begin{abstract}
Аннотация. В статье рассматривается вопрос значения цветового оформления спортивных объектов с точки зрения психофизиологического комфорта посетителей. Исследование проводилось в два этапа. Первым этапом служило анкетирование, в ходе которого было определено значение комфорта для двух групп респондентов общей численностью 289 человек, а также оценена степень важности для респондентов данных групп основных показателей комфорта спортивных объектов. Результаты исследования показали, что комфорт, внутренняя стилистика и цветосветовое оформление спортивного объекта имеют важное и не последнее значение для различных категорий посетителей спортивных объектов. Вторым этапом проводилось исследование с помощью метода экспертной оценки (метод Дельфи), в ходе которого было оценено цветовое оформление спортивнотренировочного блока (СТБ) «Снежный» (кластер «Сопка», г. Красноярск) c точки зрения создаваемого уровня психофизиологического комфорта у потребителей услуг. Результат проведенной экспертной оценки показал, что уровень психофизиологического комфорта, создаваемого цветовым оформлением СТБ «Снежный», оценивается как «близкий к повышенному» и «повышенный». Исследование показало, что цветовые решения, применяемые при оформлении спортивных объектов, могут иметь значение в создании психофизиологического комфорта у посетителей, а следовательно, могут быть использованы как один из факторов успеха при разработке маркетинговой стратегии спортивных объектов.
\end{abstract}

Ключевые слова: спортивный объект, психофизиологический комфорт, значение комфорта, цветовое оформление.

Научная специальность: 13.00.04 - теория и методика физического воспитания.

\section{Введение}

На этапе проектирования и строительства спортивные объекты наполняют функциями и их характеристиками для последующего формирования и реализации набора услуг потребителям (Aristova et al., 2016). Заложенные характеристики функциональных зон, архитектурно-планировочных, конструктивных, инженерных и технологических решений служат обеспечению безопасности, комфортности и экономичности функционирования и эксплуатации спортивных объектов.

На сегодняшний день на государственном уровне закреплен спектр функций и их характеристик, наличие которых обяза- тельно при проектировании, строительстве и эксплуатации спортивных объектов. Анализ данных функций и характеристик показал, что их основным содержанием является обеспечение безопасности всех структурных компонентов спортивного объекта и в меньшей степени спортивная составляющая - соответствия правилам вида спорта (GOST R55529-2013; GOST R52024-2003; GOST R52025-2003; SR2.1.2.3304-15, 2015; Prikaz Ministerstva stroitel'stva i zhilishchnokommunal'nogo ..., 2017). При этом отсутствует должное внимание к целому ряду не менее значимых факторов. Например, к цветовому оформлению, способствующему созданию комфорта на спортивном 
объекте. Имеющиеся требования к цветовому оформлению спортивного объекта относятся не к объекту в целом, а лишь к помещению спортивного зала и носят сугубо утилитарный характер (SP 31-112-2004, 2005). Вместе с тем, цвет имеет значение в различных областях жизни человека (Breslav, 2000; Mikkonen, 2018; Pakhomova, 2017; Potokina, 2010), в том числе в создании комфорта зданий, сооружений и помещений (Werner, McClain, 2016; Stroeva, 2019). При этом под комфортом понимается психофизиологическое состояние, в котором находится человек, характеризующееся, благодаря условиям внешней и внутренней среды, отсутствием ощущений напряжения (Argyll, 2008; Bleikher, Kruk, 1995; Zhmurov, 2012; Niyazbaeva, 2009).

Цель настоящего исследования состояла в определении значения комфорта для различных целевых групп потребителей услуг спортивных объектов г. Красноярска.

\section{Методы исследования}

Первый этап исследования проходил в 2019 году посредством анкетирования на базе электронного ресурса «Google Формы». Для проведения опроса были разработаны и апробированы анкеты различного содержания для двух групп респондентов (далее «Категория № 1 », «Категория № 2») целевой аудитории. Один из разделов анкет был посвящен значению комфорта при выборе и посещении спортивного объекта. В данном разделе предлагались варианты ответа на вопрос о том, какое значение имеет комфорт при выборе и посещении спор- тивного объекта. Возможные варианты ответов на данный вопрос отражены в табл. 1.

Также респондентам обеих групп были предложены дополнительные 68 критериев, определяющих основные показатели комфорта, в том числе «внутренняя стилистика и цветосветовое оформление спортивного объекта». Вместе с этим, в ходе исследования респонденты определяли цвета, которые вызывают у них ощущение максимального психофизиологического комфорта при посещении спортивного объекта.

В категорию № 1 вошли следующие социальные группы: 1) действующие спортсмены; 2) спортсмены, закончившие соревновательную деятельность, но продолжающие заниматься физической культурой и спортом; 3) спортсмены, закончившие соревновательную деятельность, но продолжающие свою профессиональную деятельность в качестве тренера по подготовке спортивного резерва; 4) спортсмены, закончившие соревновательную деятельность, но продолжающие свою профессиональную деятельность в качестве тренера по оказанию физкультурных услуг населению (фитнес-центры); 5) занимающиеся физической культурой и спортом круглогодично по 2-3 раза в неделю; 6) занимающиеся физической культурой и спортом сезонно/периодически; 7) государственные служащие в области физической культуры и спорта; 8) администраторы и управленцы в области физической культуры и спорта; 9) организаторы спортивно-массовых мероприятий и event-менеджеры в области физической культуры и спорта; 10) иные специалисты

Таблица 1. Варианты ответов на вопросы анкеты

Table 1. Options for responding to the questionnaire

\begin{tabular}{|c|l|}
\hline № п. п. & \multicolumn{1}{|c|}{ Ответ } \\
\hline 1 & Один из главных критериев, на основании которых выбирается спортивный объект \\
\hline 2 & Буду рад, если объект окажется комфортным, но специально к этому не стремлюсь \\
\hline 3 & Никогда об этом не задумывался \\
\hline 4 & $\begin{array}{l}\text { Буду рад, если спортивный объект окажется комфортным, но отсутствие комфорта } \\
\text { не расстроит }\end{array}$ \\
\hline 5 & Другие варианты ответов \\
\hline
\end{tabular}


в области физической культуры и спорта. Всего в категорию № 1 вошел 231 человек. Из них женщин - 184, мужчин - 47.

В категорию № 2 вошли другие социальные группы: 1) посетители спортивноразвлекательных мероприятий: 2) зрители, болельщики, фанаты и активно интересующиеся каким-либо видом спорта (командой, спортсменом); 3) родители (законные представители) и родственники спортсменов, занимающихся физической культурой и спортом. Всего в категорию № 2 вошло 58 человек. Из них 38 женщин и 20 мужчин. Всего в опросе приняли участие 289 человек.

\section{Результаты и обсуждение}

В результате опроса было определено значение комфорта при выборе спортивных объектов для двух категорий целевой группы. Для категории № 1 как для женщин, так и для мужчин комфорт является одним из главных критериев, на основании которых выбирается спортивный объект - 41,8 и 47,8 \% соответственно (рис. 1 ). Для категории № 2 целевой группы как для женщин, так и для мужчин комфорт также служит одним из главных критериев, на основании которых выбирается спортивный объект - 43,5 и 45,5 \% соответственно (рис. 2).
Из 68 показателей комфорта спортивного объекта, предложенных для женщин категории № 1, первые три места заняли следующие: 1) близость к месту проживания, 2) уровень обеспеченности элементами инфраструктуры, 3) близкое расположение остановок общественного транспорта. У мужчин первые три места заняли: 1) близость к месту проживания, 2) эргономика и функциональность пространства, 3) место расположения в общей городской застройке.

В категории № 2 у женщин первые три места заняли следующие показатели: 1) близость к месту проживания, 2) близкое расположение остановок общественного транспорта, 3) уровень обеспеченности элементами инфраструктуры. У мужчин первые три места заняли: 1) близость к месту проживания, 2) наличие парковочных мест, 3) безопасность спортивного объекта.

Вместе с тем, из 68 показателей комфорта спортивных объектов такой показатель, как «внутренняя стилистика и цветосветовое оформление спортивного объекта», у женщин категории № 1 целевой группы расположился на 27 месте из 68. У женщин категории № 2 - на 46 месте. Этот же показатель комфорта спортивных объектов у мужчин категории № 1 распо-

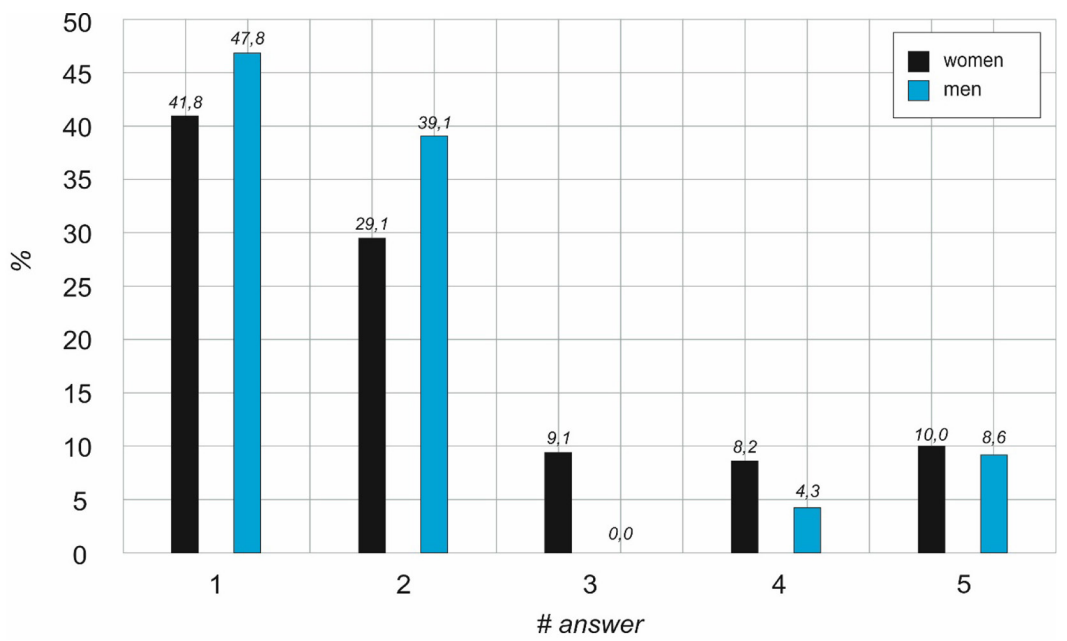

Рис. 1. Значение комфорта для лиц категории № 1 (№ ответов на вопросы табл. 1)

Fig. 1. The significance of comfort for category 1 (responses according to Table 1 ) 


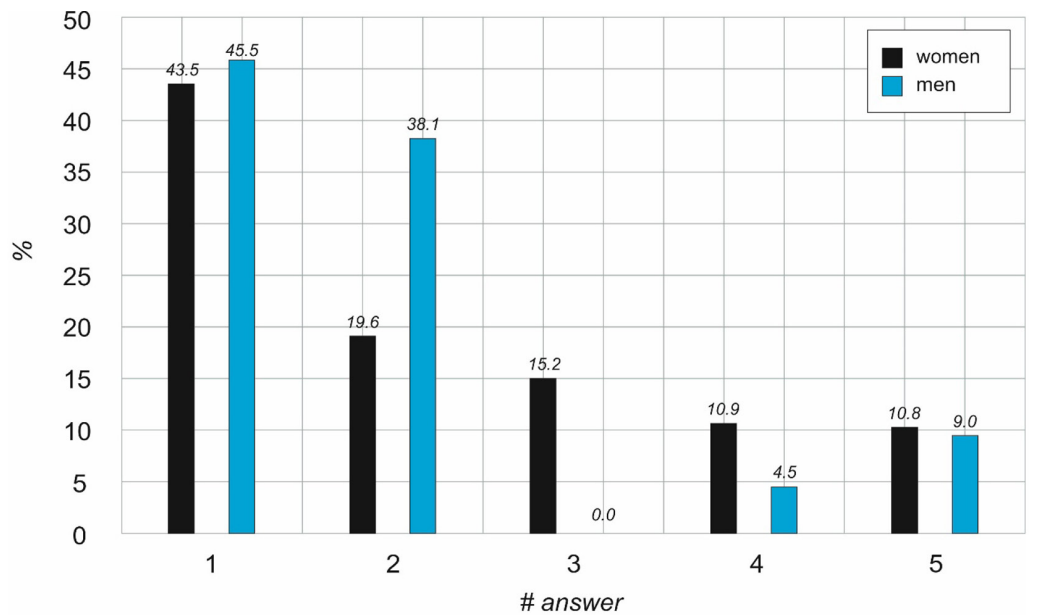

Рис. 2. Значение комфорта для категории № 2 (№ ответов на вопросы табл. 1)

Fig. 2. The significance of comfort for category 2 (responses according to Table 1 )

1-е место

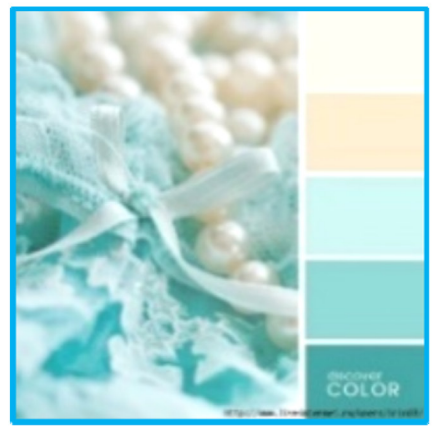

3-е место

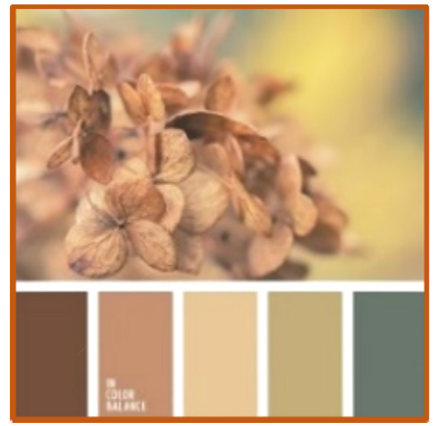

2-е место

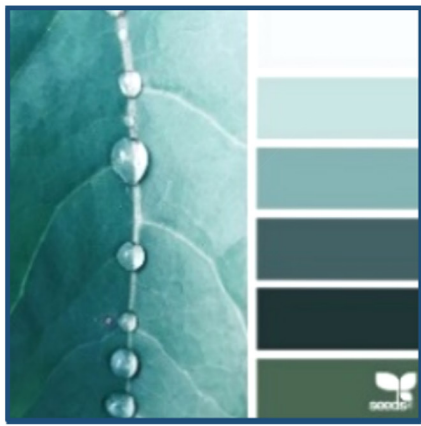

4-е место

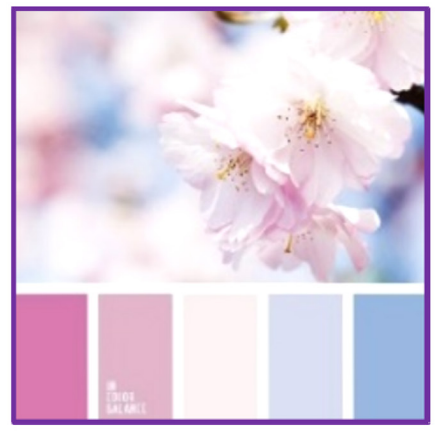

Рис. 3. Цветовые палитры (Romanuke, 2017)

Fig. 3. Color palettes (Romanuke, 2017)

ложился на 25 месте, а у мужчин категории № 2 - на 15 месте.

При определении цвета, вызывающего ощущение максимального психофизиоло- гического комфорта при посещении спортивного объекта, респонденты категории № 1 и категории № 2 отдали свои предпочтения цветам, представленным на рис. 3. 
Таблица 2. Фрагмент массива данных, отражающих многоуровневую экспертную оценку цветовых решений СТБ «Снежный»

Table 2. A fragment of the data set reflecting the multi-level expert evaluation of STB "Snezhnyi” color solutions

\begin{tabular}{|c|c|c|c|c|c|c|c|c|c|}
\hline \multirow[b]{2}{*}{$\begin{array}{c}\text { Объект оценки } \\
\text { (помещения СТБ } \\
\text { «Снежный) }\end{array}$} & \multirow[b]{2}{*}{ 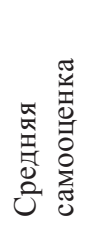 } & \multicolumn{4}{|c|}{ Первый этап } & \multicolumn{4}{|c|}{ Третий этап } \\
\hline & & 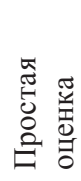 & 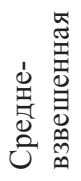 & 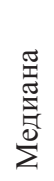 & 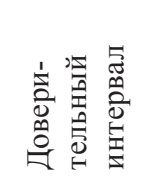 & 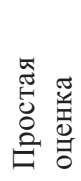 & 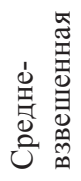 & 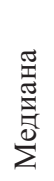 & 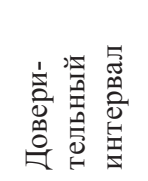 \\
\hline Вестибюль & 6,4 & 7,6 & 7,78 & 8 & {$[7 ; 9]$} & 7,3 & 7,2 & 8 & {$[6,5 ; 7,5]$} \\
\hline Душевые & 6,4 & 8 & 8,06 & 8,5 & {$[6,25 ; 8,75]$} & 8 & 8,04 & 8,5 & {$[6,75 ; 8,25]$} \\
\hline Комната тренера & 6,4 & 7 & 6,9 & 7 & {$[5,5 ; 8,5]$} & 7 & 6,87 & 7 & {$[6,25 ; 8,75]$} \\
\hline Коридоры & 6,4 & 7,1 & 7,01 & 7,5 & {$[6,25 ; 8,75]$} & 7 & 6,89 & 7 & {$[7 ; 9]$} \\
\hline Раздевалки & 6,4 & 7,4 & 7,34 & 8 & {$[4,75 ; 8,25]$} & 7 & 6,89 & 6 & {$[4,25 ; 6,75]$} \\
\hline Рекреации & 6,4 & 7,9 & 7,78 & 8 & {$[6,25 ; 8,75]$} & 8 & 7,87 & 8 & {$[6,75 ; 8,25]$} \\
\hline
\end{tabular}

С целью подтверждения полученных в ходе первого этапа данных, относящихся к цвету, вызывающему ощущение максимального психофизиологического комфорта при посещении спортивного объекта, нами был организован и проведен второй этап исследования. На данном этапе был выбран спортивный объект (СТБ «Снежный», кластер «Сопка», г. Красноярск), цветовое оформленное которого максимально соответствовало одному из цветовых решений рис. 3 (1-е и 2-е места). Для определения уровня комфорта вариантов цветового оформления СТБ «Снежный» использован метод экспертных оценок метод Дельфи. В проведении экспертной оценки приняли участие 10 экспертов, являющихся специалистами различных сфер профессиональной деятельности: психологи, дизайнеры, государственный служащий в области физической культуры и спорта, администратор коммерческой физкультурно-спортивной организации, инструктор-методист муниципального учреждения, спортсмен (мастер спорта России), спортсмен - инструктор регионального центра спортивной подготовки. В ходе проведения исследования экспертам предлагалось оценить цветовое оформление спортивно-тренировочного блока «Снежный» с точки зрения создания у них ощущения психофизиологического комфорта по 10-балльной шкале и прокомментировать свой ответ. Приведенные в табл. 2 результаты показали, что с точки зрения создания ощущения психофизиологического комфорта цветовое оформление спортивно-тренировочного блока «Снежный» располагается между 7 и 8 баллами, что соответствует характеристикам «близкое к повышенному» и «повышенное» ощущение психофизиологического комфорта. Эти данные подтвердили результаты, полученные в ходе первого этапа исследования.

Указанные к оценкам комментарии показали, что помимо самого цвета, используемого для цветового оформления, важное значение имеет сочетание цветов и их гармоничность.

\section{Заключение}

Результаты исследования позволяют сделать вывод о том, что цветовое оформление в создании комфорта спортивных объектов имеет значение. Вместе с тем, недостаточность научно-методического обеспечения в области цветовой организации объектов, а также неоцененность смыслового и культурологического значений цвета в организации предметнопространственной среды привносят хаос, 
примитивность решений или, напротив, усложнение цветовой среды, которое функционально, информативно и эстетически не оправданно. Если использовать разнообразные цветовые ассоциации, цвет может способствовать созданию психофизиологического комфорта, особого эмоционального настроя, нейтрализации неблагоприятных условий, связанных с эксплуатацией объекта, а также яркого запоминающегося образа, связанного не только с функциональным и эксплуатационным, но и с его эмоциональ- ным содержанием (Koshkin, 2000). Данный фактор может оказать влияние не только на эстетическую привлекательность спортивного объекта, но и на психическое и физиологическое здоровье и состояние организма посетителей в целом. В том числе он может позволить увеличить возможность спортсменов показать высокий спортивный результат, а также повысить интерес к спортивному объекту и, как следствие, его социально-экономическую эффективность (Maltsev et al., 2018; Shafranskaya, 2008).

\section{Список литературы / References}

Argyll, M. (2008). Psikhologiya schast'ya [Psychology of happiness]. SPb: Peter, 217.

Aristova, L.V., Varaksin, P.A., Smirnitskiy, N.S. (2016). Ekspluatacionnoe pereustrojstvo sportivnyh sooruzhenij [Operational reconstruction of sports facilities]. In Internet-zhurnal «Naukovedenie» [Internet journal «Science of Science»], 8, 2. DOI: http://naukovedenie.ru/PDF/147TVN216.pdf

Bleikher, V.M., Kruk, I.V. (1995) Tolkovyy slovar' psikhiatricheskikh terminov [Explanatory dictionary of psychiatric terms]. Voronezh, 162.

Breslav, E. (2000). Tsvetopsikhologiya i tsvetolecheniye dlya vsekh [Color psychology and color therapy for everyone]. SPb: B. \& K., 212.

GOST R 52024-2003 Uslugi fizkul'turno-ozdorovitel'nyye i sportivnyye. Obshchiye trebovaniya [State Standard R 52024-2003 Physical fitness and sports services. General requirements] (2003).

GOST R 52025-2003 Uslugi fizkul'turno-ozdorovitel'nyye i sportivnyye. Trebovaniya bezopasnosti potrebiteley [State Standard R 52025-2003 Physical fitness and sports services. Consumer safety requirements] (2003).

GOST R 55529-2013 «Trebovaniya bezopasnosti pri provedenii sportivnykh i fizkul'turnykh meropriyatiy. Metody ispytaniy» [State Standard R 55529-2013 "Safety Requirements for Sports and Physical Culture Events. Test methods"] (2013).

Koshkin, D.F. (2000). Printsipy koloristicheskoy organizatsii ob"yektov dizayna arkhitekturnoy sredy: avtoref. dis. ... kand. arkhitektury: 18.00 .01 [Principles of the coloristic organization of objects in the design of the architectural environment: author. dis. ... Candidate of Architecture: 18.00.01]. Kazan, 21.

Maltsev, A.A., Nasonov, V.V., Khristov, V.V. (2018). Planirovaniye trenirovochnykh zanyatiy po plavaniyu s uchetom zagruzhennosti sportivnogo basseyna (na primere TSOP «Tyumen'-dzyudo») [Planning of training sessions in swimming taking into account the workload of the sports pool (on the example of the TsOP «Tyumen-judo»)]. In Uchenyye zapiski universiteta imeni P.F. Lesgafta [Scientific notes of the P.F. Lesgaft], 5, 170-174.

Mikkonen, K.F. (2018). Tsvetoterapiya zabolevaniy razlichnoy etiologii: stat'ya $v$ sbornike konferentsii [Color therapy of diseases of various etiologies: an article in the conference collection]. In Fundamental'nyye i prikladnyye nauchnyye issledovaniya, aktual'nyye voprosy, dostizheniya i innovatsii [Fundamental and applied research, topical issues, achievements and innovations], 253-256.

Niyazbaeva, N.N. (2009). Psikhologicheskoye obosnovaniye obespecheniya komforta mladshikh shkol'nikov v obrazovatel'noy deyatel'nosti [Psychological substantiation of providing comfort for younger students in educational activities]. In Elektronnyy zhurnal «Psikhologicheskaya nauka i obrazovaniye» [Electronic journal «Psychological Science and Education»], 3, 1-18.

Pakhomova, A.V. (2017). Tsvetoterapiya kak novaya otrasl' svetodizayna [Color therapy as a new branch of lighting design]. In Problemy kachestva graficheskoy podgotovki studentov v tekhnicheskom vuze 
traditsii $i$ innovatsii [Problems of the quality of graphic training of students in a technical university of tradition and innovation], 1, 436-440.

Postanovleniye Glavnogo gosudarstvennogo sanitarnogo vracha RF «Ob utverzhdenii SP 2.1.2.330415 «Sanitarno-epidemiologicheskiye trebovaniya k razmeshcheniyu, ustroystvu i soderzhaniyu ob"yektov sporta» ot 28.09.2015 № 61 [Resolution of the Chief State Sanitary Doctor of the Russian Federation "On the approval of SR 2.1.2.3304-15" Sanitary and epidemiological requirements for the location, arrangement and maintenance of sports facilities» dated September 28, 2015 No. 61] (2015).

Potokina, T.M. (2010). Tsvetovoye konstruirovaniye sotsial'nogo prostranstva avtoref. dis. ...kand. filosofskikh nauk: 24.00.01 [Color construction of social space: author. dis. ... Cand. Philosophical Sciences: 24.00.01]. Volgograd, 5.

Prikaz Ministerstva stroitel'stva i zhilishchno - kommunal'nogo khozyaystva Rossiyskoy Federatsii "Ob utverzhdenii svoda pravil "Sportivnyye sooruzheniya. Pravila proyektirovaniya" ot 14.11.2017 №1536/ pr. [Order of the Ministry of Construction and Housing and Communal Services of the Russian Federation "On approval of the set of rules" Sports facilities. Design rules" dated 14.11.2017 No. 1536 / pr.] (2017).

Romanuke, A. (2017). In color balance. Available at: https://color.romanuke.com/o-resurse/

Shafranskaya, A.N. (2008). Fiziologi - gigiyenicheskaya otsenka mikroklimata i problema upravleniya kachestvom vozdushnoy sredy krytykh sportivnykh sooruzheniy [Physiologists - hygienic assessment of the microclimate and the problem of air quality management in indoor sports facilities]. In Vestnik vosstanovitel'noy meditsiny [Bulletin of Restorative Medicine], 2, 36-39.

SP 31 - 112 - 2004 (2005). Svod pravil po proyektirovaniyu i stroitel'stvu. Fizkul'turno-sportivnyye zaly. Chast' 1. [Code of rules for design and construction. Physical culture and sports halls. Part 1]. Moscow, 180.

Stroeva, N.N. (2019). Arkhitekturno - tipologicheskiye printsipy formirovaniya velnes - tsentrov [Architectural and typological principles of wellness centers formation]. Moscow, 36-40.

Werner, L., McClain, A. (2016). Color and Visual Comfort. Available at: https://soa.utexas.edu/

Zhmurov, V.A. (2012). Bol'shaya entsiklopediya po psikhiatrii, [Great Encyclopedia of Psychiatry]. In Natsional'naya psikhologicheskaya entsiklopediya [National Psychological Encyclopedia]. Available at: http://vocabulary.ru/dictionary/978/word/kliniko-psihopatologicheskii-metod-isledovanija 